\title{
Corrosion Behaviour of Low-Alloy Steel with Titanium Addition Exposed to Seawater Environment
}

\author{
Zhenguang Liu ${ }^{1}$, Xiuhua Gao ${ }^{1, *}$, Linxiu $D u^{l}$, Jianping $L^{1}{ }^{1}$, Ping $L i^{2}$ \\ ${ }^{1}$ The State Key Laboratory of Rolling and Automation, Northeastern University, Shenyang 110819, \\ Liaoning, China; \\ ${ }^{2}$ College of Chemistry, Jilin University and MacDiarmid Laboratory, Changchun 130021, Jilin, China. \\ *E-mail: liuzhenguangabcd@163.com
}

doi : $10.20964 / 2016.08 .25$

Received: 10 May 2016 / Accepted: 30 May 2016 / Published: 7 July 2016

\begin{abstract}
Immersion experiment was performed to study the early seawater corrosion behaviour of pipeline steel with titanium addition by analysing microstructure characteristics of designed steel, corrosion kinetics, corrosion phases and surface morphology. The experimental results demonstrate that the microstructure of designed steel is tempered martensite and the Ti-rich particles and Cr-rich particles are observed. The corrosion rate of early seawater corrosion decreases in the exponential format. The corrosion behaviour of designed steel is divided into two stages. The Cr-rich compounds are mainly formed at the first stage and the ferrous corrosion products deposit on the coupon surface at the second stage. The main corrosion phases are goethite and lepidocrocite, and Cr-substituted goethite is also found. The titanium element accelerates the formation of the compact and dense corrosion products free of pores, which is beneficial for corrosion resistance.
\end{abstract}

Keywords: corrosion behaviour; seawater; pipeline steel; titanium; precipitation particles

\section{$\underline{\text { FULLTEXT }}$}

(C) 2016 The Authors. Published by ESG (www.electrochemsci.org). This article is an open access article distributed under the terms and conditions of the Creative Commons Attribution license (http://creativecommons.org/licenses/by/4.0/). 